The Review of Finance and Banking

print ISSN 2067-2713, online ISSN 2067-3825

Volume 12, Issue 2, Year 2020

http://dx.doi.org/10.24818/rfb.20.12.02.01, Pages 103-114

\title{
FACTORS AFFECTING THE ADAPTABILITY OF DIGITALIZED MODE OF PAYMENT AMONG THE SMALL TRADERS: A LOGIT MODEL ANALYSIS
}

\author{
POLAKSHI BHATTACHARYYA BARUAH AND ANUPAM DUTTA
}

\begin{abstract}
Digitalization has gained momentum in recent years in all sphere of life around the globe. It has become an important factor of defining modernization, and instrumental in speeding up economic growth by ensuring more transparency. After demonetization and emphasis on cashless transaction, digitalized mode of payment is being prioritized. Accordingly, government of India launched several schemes focusing on imparting training on digital literacy, but research shows that a section of population is still not adopting this digitalization process. This study tries to find the factors responsible for excluding a section of the people, especially the people of rural and semi urban area from this digitalized system. Accordingly, a survey was conducted with the bamboo craft man of Raipur cluster of Barpeta District of Assam, India, who is involved in small enterprises involving bamboo crafting. Direct interaction was being done with the respondents regarding the various problems and inconvenience faced in adapting the new system. A logit regression model has been used to highlight the impact of various socio-economics factors, level of awareness about the new system of digitalization on their adaptability to the digitalized mode of payment.
\end{abstract}

\section{INTRODUCTION}

In their study, Kumar (2015) stated that the government, in order to make all financial transaction more transparent, combat tax evasion through black money and to encourage country towards a cashless economy, took the step of demonetisation on 8th November 2016 and stressed on prioritizing the role of digitalized payment. The study also believed that to bring a change in the behaviour pattern of the people it is necessary to bring some changes in the economic system. Post demonetisation there is a significant improvement in the percentage of people using the cashless method of payment. The improvement in the use of digitalized payment is being evident in the annual report of the Reserve Bank of India for the financial year 2016-17. The report stated that the volume of transactions through digital payment systems witnessed a 56 per cent increase, with the value of funds increasing by 24.8 per cent (Maji 2017). Punwatkar and Verghese (2018) in their research work revealed that a section of people adapted the new system of digitalized payment realizing its comparative advantages over cash payment, in terms of availability, convenience, accessibility and time saving.

To boost the level of adaptability of the people for the new system of payment the government of India have undertaken various measures like, The National Payment Corporation of India (NPCI) who envisaged a responsibility to guide India towards a cashless society. NPCI has been directed to ensure a technical and security audit of the same to ensure that the technical

Received by the editors December 1, 2019. Accepted by the editors July 24, 2020 .

Keywords: Financial literacy, digitalization, financial technology, adaptability.

JEL Classification: G28, JEL: G28.

Polakshi Bhattacharyya Baruah, PhD, Assistant Professor of Economics, University of Science \& Technology, Meghalaya, India. E-mail: polakshibb@gmail.com.

Anupam Duttar, PhD, Associate Professor, University of Science \& Technology, Meghalaya, India. E-mail: eradutta@gmail.com.

This paper is in final form and no version of it will be submitted for publication elsewhere. 
integrity of the process is maintained. Various Schemes like Lucky Grahak Yojana and DigiDhan Vyapar Yojana have been implemented to encourage the common man to adopt the digitalized system. (Press Information Bureau Government of India NITI Aayog 15 December 2016).

To make these schemes more attractive the government have offered some cash awards to consumers and merchants who utilize digital payment instruments. The prizes range from Rupees 1000 to Rupees 1 crore and the transactions permitted are from Rupees 50 to Rupees 3000. The motive of these schemes is not only to give a boost to cashless transactions but to make it more inclusive in nature by focusing more on poor, lower middle class and small businesses to adapt the system of digitalization mode of payment (Joshi and Desai 2017).

Apart from various schemes the government have also expanded the digital payment infrastructure in rural areas, through National Bank for Agriculture and Rural Development (NABARD) by extending financial support to eligible banks for deployment of two Point of Sale (PoS) devices each in one Lakh villages with population of less than 10,000. These PoS machines are intended to be deployed at primary cooperative societies, milk societies and agricultural input dealers to facilitate Agri-related transactions through digital means and serve 75 crore populations (Jain 2018).

As various empirical studies like Arif (2015), Ghaffar \& Sharif (2016) and Prasad \& Meghwal (2017) have claimed that although various measure are adopted by the government to make the financial system more digitalized, accessibility and adaptability of digitalized system is still a big challenge for a country like India. These studies have highlighted that a large section of rural as well as semi-urban population is not comfortable with the digitalized mode of payment system as there is wide variation in the level of financial literacy among the population. There is a need to address the problem of excludability of a section of people from the digitalized system. If this is not emphasised, then the digitalization process cannot be a successful one in any real sense. This study tries to find the various socio-economics factors that affect the adaptability of the digitalized system by a section of people of the nation.

\section{Literature REVIEW}

Many searches were carried out addressing the issue of digital financial literacy during the period of 2015 onward, as it was the period when digitalisation of the financial system was the prime focus. The research done during this time focused on the area of various hindrances on the successful implementation and operation of various schemes on financial literacy.

Arif (2015) focused on the relationship between financial literacy and its influence on investment decision. The data was collected from 154 respondents through modified questionnaire containing questions related to the demography of the investors, factors affecting the investment decisions and the financial literacy level of the individual investors at Karachi Stock Exchange. The study concluded that the financial literacy level of the investors was below average. Significant differences in financial literacy was found between the respondents regarding age, gender, work activity and marital status of the respondents. The study of Malady (2016) pointed out that simply having a digital banking credential does not necessarily improve the level to financial literacy as most of the people processing digital banking credentials, hesitates to use it because of lack of confidence in the system. Caruana (2016) reveals that the costs of securing customers data on digital finance sometimes exceed the cost of offering the services. Thus, hindering the efficiency and profitability of service providers and thereby affecting the smooth function of the whole system. Gender gap is another issue pointed out in the study of Aggarwal and Gupta (2016), where the study revealed that the participation level of female is very insignificant in the stock market. This study stated that the low financial literacy level and lack of risk attitude are also equally accountable for the difference in participation level in financial matters between male and female. Finau et.al (2016) examined the perception of digital financial services (DFS) among the rural population; this study intended to find whether the DFS is provided through mobile network operator individually or in collaboration with banks. The findings of the study 
reveal that the process was hindered by the implicit cost the agent impose on the consumer; moreover, the rural population are not so mobile friendly, yet another obstacle for the system. A similar study was done in Pakistan by Ghaffar \& Sharif (2016). Their study revealed that the person with financial knowledge are more careful in spending and do take interest in learning digital financial system. Addressing the gender issue, it was found that females are comparatively less knowledgeable than the males regarding the digitalized financial system. Prasad \&. Meghwal (2017) conducted a study in Udaipur of Rajasthan, to see the level of awareness of digital financial literacy. They found that the type of occupation has a significant influence in the decision of using the digitalized financial system. Also, people who are in the service sector are welcoming the digitalized system compared to the people in non-service sectors. This might be because the service class people have disclosed money. Thus, they do not hesitate in doing transactional activities through a digital platform, compared to the non-service sector who hesitate to disclose their income. Wyman (2017) in a report submitted to the Asian Development Bank stated that the main barrier to financial inclusion in the South Asian countries like Indonesia, Cambodia and Myanmar is the presence of high illiteracy rate. However, with the introduction of the digital mode of payment and proper training imparted in using the system has helped to reduce the gap in financial inclusion. Urbancikova et al (2017) made a study in Slovakia to identify various social, economic and regional factors that have a significant impact on the digital literacy of the people by using a regression model for cross-sectional data. The finding of the study revealed that education, age, income and household type are the most significant factors whereas region, gender and nationality are insignificant factors in influencing the level of digital literacy. Harris et al (2017) tried to find the digital divide in Western Australia by looking at the accessibility of information technology (IT). The sample size of the study is 1,351 respondents between the ages of 6 years and 17 years. The study concludes that there exists wide variation in the level of accessibility of information technology like computer and mobile phones depending on the socioeconomic status of the sample population. The respondents with higher socioeconomic status have more exposure to IT activities both at school and at home. Whereas the respondents from lower socioeconomic status are more exposed to non-academic related IT activities. The authors stated that this pattern of accessibility to IT will adversely affect the economic, academic and health outcomes of the young people. Punwatkar and Verghese (2018) conducted a study to see as to what are the factors that affect the adaptation of e-wallets as a prominent mode of digital payment. The results of the study shows that factors like trust in electronic transactions, opportunity cost of using e-wallet, maintenance of private information security, quality of service provided, technical know-how and intention to use have a positive effect on the adoption behaviour of the people to digital payment system. The study of Kuek \& Hakkennes (2019) is related to digital literacy and health care. The study analysed the attitudes of the health staff members in using the electronic health record system. A survey was conducted with a sample of 407 respondents, to see whether age of the respondents is a significant factor that influences the adaptability of electronic health record system. The respondents were grouped either below 50 years of age or above or equal to 50 years of age. The study concludes that most of the respondents (70 per cent) shows positive attitude toward digitalization. Yet a section of the respondents of above 50 years of age were finding problems in using the new system. Arguably this can be solved by providing more intensive training to those respondents in using the electronic health record system.

The studies by Juan Jung (2015), Yongfu Huang (2017) and Hans (2018) emphasised the digitalization process to improve connectivity among the regions and all-round economic growth. This study also agrees that digitalization can help a region in improving its connectivity with other regions of the country. However, the researchers believe that it is important to find the level of adaptability to the digitalization process of the local people of a region before it goes for online trade connectivity with other regions. Hence this study confined itself only to the factors affecting the adaptability to digitalized mode of payment of small traders. 
The above literature review reveals that various studies (Urbancikova, 2017; Wyman, 2017 and Harris, 2017) have been carried out in different part of the globe to explore the adaptability of the digitalization system in the field of health and education and also its applicability and adaptability in the financial services sectors. In India most of the studies like Meghwal, (2017), Bora (2017) and Panigrahi (2019) relating to adaptability of digitalization in the financial sectors have been made after the demonetization in 8th November 2016. These studies cover different parts of India. Debatably few studies have been made in the north-eastern part of India relating to these topics. Therefore this study tries to find out the level of awareness of the people relating to digitalization system and what are the factors hindering the process of adapting the system of digitalization, by selecting a sample of respondents from Barpeta district of state Assam of north eastern part of India.

\section{Research Design and Methodology}

The awareness of the people about the digitalized system, including its advantages over and above cash payment can be helpful in adapting the new system. The concept literacy, awareness and adaptability are interlinked in the process of adapting a new system (Punwatkar and Verghese (2018). The study of E.H Baker (2014) established a link between the socioeconomic status and awareness of health facilities and availing of health services. This study revealed that there is a positive relationship between the three variables.

From the foregoing, this study also tries to establish the link between the socioeconomic status of the people, awareness of the people and their adaptability to a new system, namely the digitalized mode of payment. In this study socioeconomic status refers to one's combined social and economic status. This study considers the three common measures of socioeconomic status: education, income, and occupation. It is surmised in this study that the socioeconomic status of a person tends to be positively related the level of awareness. Awareness is the knowledge of something existing, its utility and disutility in practice. Adaptability is the ability to change his/her actions, or approach of doing things in order to suit a new situation. The interrelation of these three concepts is shown in the figure below.

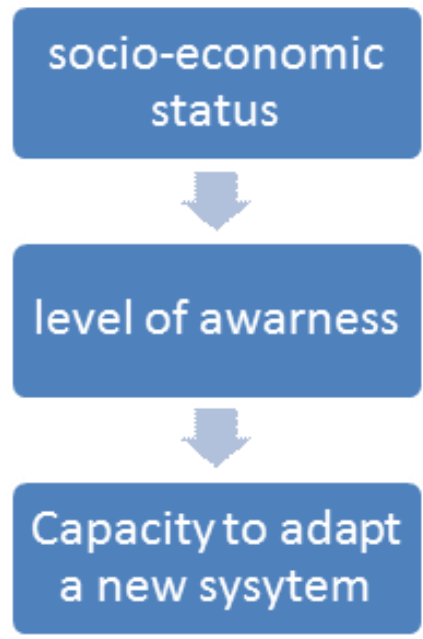

This study aims to explore the socio-economic status of the bamboo craft man and try to find out which factors among the various socio-economics factors like income; literacy, occupation age etc impact their adaptability to digitalization. The study also tries to find the level of awareness of the people about the various instruments of digitalized system. Finally, the researcher aimed to find which socio economics factor/s and whether the levels of awareness of technology have any significant influence on the adaptability of the digitalized system among the bamboo craft man of Barpeta district. 
This study tries to answer as to which socio-economic factors of the selected sample have the highest influence in adapting the digitalized system of payment.

A sample of 100 bamboo craft man of Raipur cluster of districts Barpeta, Assam who are beneficiary of Jeevanjyoti Swaniyojan Yojana (A self-employment generation programme of Assam implemented by State Institute of Panchayat and Rural Development) are selected randomly. The Jeevanjyoti Swaniyojan Yojana scheme is implemented by The State Institute of Panchayat and Rural Development (SIPRD), the scheme focusses on employment generation. It is a demand driven project of the state government of Assam, India. The Financial assistance through institutional credit is given up to Rupees 6.00 Lakhs depending upon the credit worthiness, situation and condition of the applicants who should be within the age group of 18 to 37 years of age. The schemes mainly finance activities of primary, secondary and tertiary sectors relating to production, processing, marketing, transportation, supply of quality inputs, small business, business, small industries, industries, services etc. (Assam chief minister's Jeevanjyoti Swaniyojan Yojana 2014). A sample of 100 bamboo craft man of Raipur cluster of districts Barpeta, Assam, who are beneficiary of Jeevanjyoti Swaniyojan Yojana (A self- employment generation programme of Assam implemented by State Institute of Panchayat and Rural Development) are selected randomly. A structured questionnaire was prepared to collect information from the sample through direct interaction. A logit model is applied to estimate the significant factors that have an influence in adapting the digitalized mode of payment. Sperandei (2014) has mentioned that the logit model is widely used when the dependent variable is dichotomous variable (which have only two categories) and the independent variables can be a scale, ordinal or nominal variables. It is a model that measures the strength and statistical significance of each independent variable with respect to the probability of moving from one situation to another, keeping constant the effect of the other variables. A logit model analyses the chance of an outcome based on the individual characteristics. As chance is a ratio, this model is the logarithm of the chance given by

$$
\log \left(\pi_{1}-\pi\right)=\beta_{0}+\beta_{1} x_{1}+\beta_{2} x_{2}+\ldots \beta_{m} x_{m}
$$

Where $\pi$ indicates the probability of an event) and $\beta_{i}$ are the regression coefficients associated with the reference group and the $x_{i}$ explanatory variables (Sperandei, 2014).

As this study is interested to predict the impact of various independent variables like age, gender, occupation, education, income, mode of payment used, frequency to visit the bank, confident level of using the ATM, use of electronic data capture machine, willingness to use electronic data capture machine on the dichotomous dependent variable (willing/ not willing to adapt the digitalized mode of payment). The logit model is given as

$$
Y_{i}=\beta_{0}+\beta_{1} x_{1 i 1}+\beta_{2} x_{2 i}+\beta_{3} x_{3 i}+\ldots \ldots \beta_{k} x_{k i}+\mu
$$

Here the independent variables like age, gender, occupation, education, income reflecting the socio-economics status and the variables namely mode of payment used, frequency to visit the bank, confident level of using the ATM, use of electronic data capture machine, willingness to use electronic data capture machine, are the parameters to measure the awareness level of the respondents.

This study also conducted a Hosmer-Lemeshow test (HL test) to see the goodness of fit of the logit model. A goodness of fit test tells us how well our data fits the model.

The Hosmer-Lemeshow test statistic is calculated with the following formula:

$$
G_{H L}^{2}=\sum_{j=1}^{10} \frac{\left(O_{j}-E_{j}\right)^{2}}{E_{j}\left(1-\frac{E_{j}}{n_{j}}\right)} \sim \chi_{8}^{2}
$$

Where:

$\chi^{2}=$ chi squared.

$n_{j}=$ number of observations in the $j^{\text {th }}$ group. 
$O_{j}=$ number of observed cases in the $j^{\text {th }}$ group

$E_{j}=$ number of observed cases in the $j^{\text {th }}$ group

Like most goodness of fit tests, here also a small $p$-value (usually under $5 \%$ ) mean that our model is not a good fit, a higher $p$-value is more likely to be acceptable (Hosmer 2013).

We used the logit model as appropriate because several quantitative studies have applied the logit model as a statistical tool of analysis; some of those are as follows. Malhotra (1984) had highlighted the scope of using the logit model in marketing research; the study stated that apart from other fields like education, health etc logit model can be efficiently applied in the field of marketing areas. Maddala (1991) has applied this model to analyse the statistical significance of the independent variable namely gender and pay scale on the level of job satisfaction, which is the dependent dummy variable. In the study of Anderson (2003), argued the increasing trend in the use of logit regression model in clinical studies. This study shows the upward up trend in the logit model by taking into consideration the percentage of papers appearing in three thoracic surgical journals, according to the year of publication. Peng, et al (2002) stated that another area where logit model is commonly applied is the studies relating to evaluation of capabilities among the students and its relation to various socio-economics factors. In the study of Ramosacaj et al (2015) has used the logit regression model to analysis the impact of the independent variables like gender, the surrounding environment of the private or public school, location of the school etc on the dependent variable that is the performance of the students in examination. Boamah (2015) used the logit model to predict social trust taking into consideration the impact of five predictor variable like highest degree earned, race, sex, general happiness and the importance of personally assisting people in trouble. The study aimed to find out which predictor among all the five predictors report to have a low social trust, the finding of the study reveals that among all the predictors the strongest predictor of low social trust was the education level of the respondents.. In another study carried out by Alzen (2018) the relationship between learning assistant and its impact on the introduction of STEM courses is being analysis by using the logit regression model. The study revealed that learning programme is consistently associated with lower failure rates in introductory STEM courses.

\section{Results and Findings}

Starting with the socio-economic profile of the respondents in terms of their terms of their age, gender, income we report the results and findings next.

Gender wise distribution of Respondent: The survey reveals that majority of the bamboo craftsman are male and very few females are associated with this occupation. Out of the total sample 82 per cent of respondents are male and only 18 per cent are female.

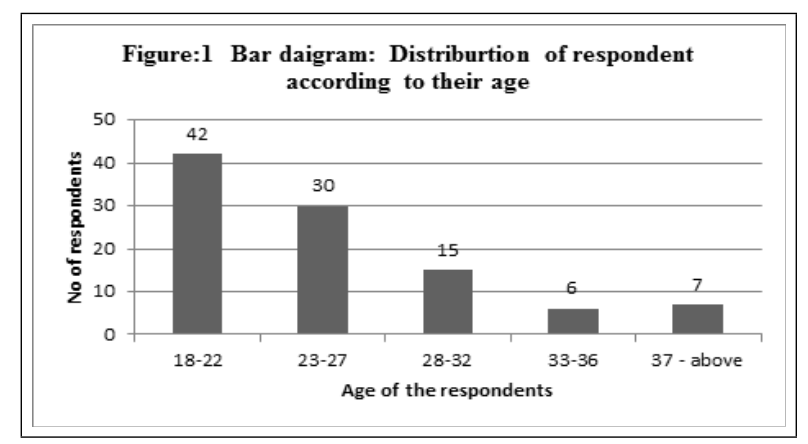

Distribution of the respondents according to their Age: Figure 1 shows that majority of the respondent are of the age group 18-22, followed by 30 per cent of the respondents at the age group of 23-27, and 15 per cent of them are in the age group of 28-32 years. About 6 per cent and 7 per cent of the sample are at the age group of 33-36 and 37 - above respectively. 
It shows that majority of the respondents are within the age of 18-22, who are have more desirability and capacity to learn and adopt new system.

Distribution of Respondents according to their Income:

The study reveals that 35 per cent of respondents are within a monthly income group of rupees 6001 to 8000 and 24 per cent are in the income group of rupees 8001 to 10,000 per month, followed by 23 per cent of respondents are in the income group of rupees 10,000 to 12,000. Though all are into the same occupation but there is a wide variation because of the variation in the bamboo items produce by them and some of the respondents also have other source of income. (figure 2)

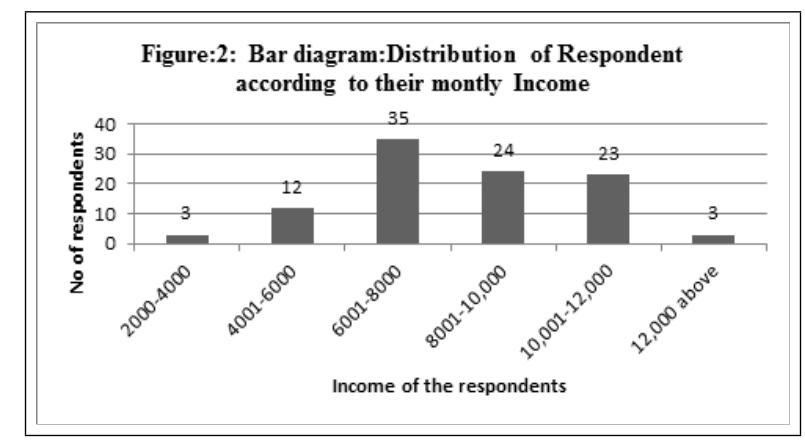

Distribution of Respondents according to their Education level:

Education is an important parameter of socio-economics profile, here in the survey it was seen that about 30 per cent of the respondents are class XI passed, 7 per cent are illiterate, 11per cent are primary level and 27 per cent of them are class VIII passed and 18 per cent are class X passed and 7per cent respondents are graduate (figure 3) It is observed that most of the respondents after passing class XII take up the business of bamboo crafting and some of them are also continuing their graduation on distance education.

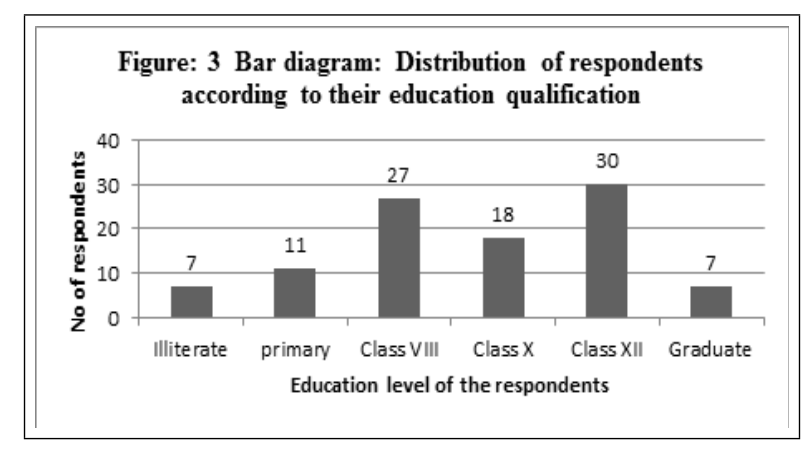

Distribution of Respondents according to their level of awareness about digitalization: The awareness of the respondents with regard to digitalization was inferred looking at their banking habit, confident level in using the ATM, download of payment app, and the mode of payment used to transfer fund.

Distribution of the respondents according to their mode of Payment Used:

It has been observed from the figure 4 that majority of them ( 55 per cent of the respondents) makes financial transaction in cash, 26 per cent of them used debit and credit card and 9 per cent of them used draft and 10 per cent used cheque to make payment. This reflects that most of them about more than 50 per cent are still using cash as the mode of payment. It has been seen that the percentage of the respondent using debit and credit cards is very negligible. 


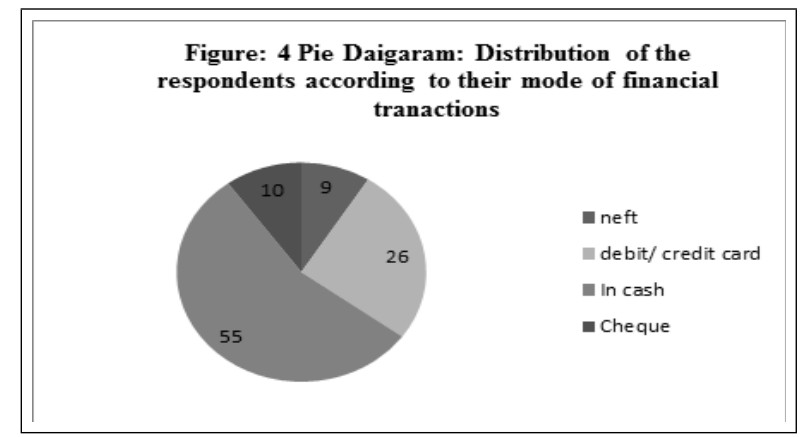

\section{Confident level of Respondents in Using the ATM:}

The level of confident in using the ATM, is measured by putting the questions like are they fully confident to go on their own and use the ATM? Do they need others help to withdraw money from the ATM? The findings (figure 5) reveals that 39 per cent of them have full confident is using it while 15 per cent of them have never used it and 46 per cent of them used it but not with full confident they fell nervous and have to take others help to use it, so it reveals that majority of the respondents are not fully confident in using the ATM.

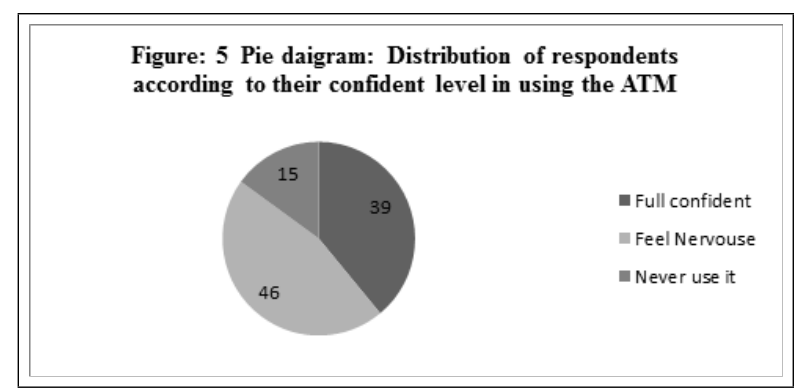

Another parameter to determine the respondents' level of adaptation to digitalization lies in availing the service of various payment apps. It was found that only 26 per cent of the respondents have downloaded the apps and rest of the respondents 74 per cent of them are not aware of it and are not willing to use it as they are not finding the system very trustworthy.

Distribution of respondents according to their desire to use Card Swipe machine for payments:

It has been observed that the in the era of digitalization card swipe machine or Electronic Data Capturing (EDC) machine have become an important device to make payment by cards. This device has been used by almost all businessmen in urban areas irrespective of the size of the business. The survey has found that among the 100 respondents only 13 of them used EDC machine and they are those craft man whose income is above 10,000 per month. 69 of them are willing to apply for the machine and 24 of them have applied for it (Figure 6).

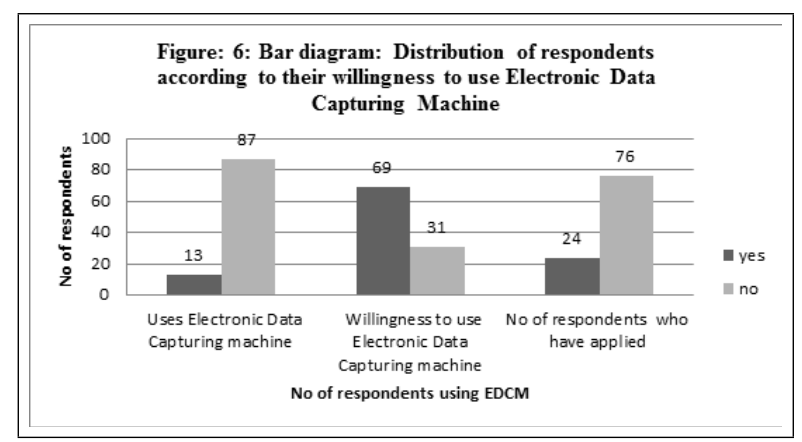

Logit Model: A logit model is used to find the various factors that significantly influence the respondents in willingness to adapt the digitalized mode of payment. The model is: 
$Y_{i}=\beta_{0}+\beta_{1} x_{1 i}+\beta_{2} x_{2 i}+\beta_{3} x_{3 i}+\beta_{4} x_{4}+\beta_{5} x_{5}+\beta_{6} x_{6}+\beta_{7} x_{7}+\beta_{8} x_{8}+\beta_{9} x_{9}+\beta_{10} x_{10}+\mu$

Where

$Y_{i}=$ Willingness to adapt the digitalization mode of payment (dummy variable)

$x_{1}=$ age of the respondents

$x_{2}=$ education level of the respondents

$x_{3}=$ gender of the respondents

$x_{4}=$ Frequency of visit to a bank

$x_{5}=$ Income of the respondents

$x_{6}=$ Mode of payments used by the respondents

$x_{7}=$ the level of confident in using the ATM

$x_{8}=$ Using Electronic Data Capturing Machine

$x_{9}=$ Willingness to apply for Electronic Data Capturing Machine

$x_{10}=$ whether bamboo crafting is primary or secondary occupation

$\beta=$ Coefficient

$\mu=$ error term

\begin{tabular}{|c|c|c|c|}
\hline \multicolumn{4}{|c|}{ Table I: Model Summary } \\
\hline Step & -2 Log-likelihood & Cox\&Snell R-Square & Nagelkerke R-Square \\
\hline 1 & $49.136^{a}$ & 0.591 & 0.791 \\
\hline
\end{tabular}

Table II: Hosmer and Lemeshow Test

\begin{tabular}{|c|c|c|c|}
\hline Step & Chi-square & Df & Sig. \\
\hline 1 & 3.697 & 8 & .883 \\
\hline
\end{tabular}

The execution of the logit model has been shown in the table 1 , the value of $\mathrm{R}$ square is 0.791 which implies that the 79.1 percent of the variation in $\mathrm{Y}$ is explained by this model, and the model can be acceptable. A Hosmer and Lemeshow goodness of fit test is also done the result of the test shows that the significant level is .883 which indicate that 88.3 percent of variation in the dependent variable is explained by this model (Table II).

\begin{tabular}{|l|c|c|c|c|c|c|}
\hline \multicolumn{5}{|c|}{ Table III: Variables in the Equation (Result of the logit model) } \\
\hline & $B$ & S.E. & Wald & Df & Sig. & Exp $(B)$ \\
\hline Age & -.151 & .102 & 2.193 & 1 & .139 & .860 \\
\hline Education & 1.874 & .498 & 14.145 & 1 & .000 & 6.513 \\
\hline Gender & -2.440 & 1.522 & 2.568 & 1 & .109 & .087 \\
\hline Frequency of visit to bank & -.063 & .618 & .010 & 1 & .919 & .939 \\
\hline Income & 1.669 & .509 & 10.762 & 1 & .001 & 5.304 \\
\hline Mode of payment & .544 & .305 & 3.180 & 1 & .075 & 1.723 \\
\hline Confident to use ATM & -.223 & .965 & .054 & 1 & .817 & .800 \\
\hline Use EDCM & 1.447 & 1.413 & 1.048 & 1 & .306 & 4.249 \\
\hline Willingness to use EDCM & -.599 & .961 & .388 & 1 & .533 & .549 \\
\hline Occupation & -1.997 & .999 & 3.999 & 1 & .046 & .136 \\
\hline Year of opening bank account & .061 & .489 & .016 & 1 & .901 & 1.063 \\
\hline Constant & -2.435 & 3.522 & .478 & 1 & .489 & .088 \\
\hline
\end{tabular}

The finding of the logit model in the Table 2 reveals that among all the independent variables education of the respondents is highly significant (.000) in influencing the decision of adapting the digitalized mode of payment, with an Exp beta value of 6.513 which implies that with very increase in education level there is a probability that the willingness to adapt the digitalized system increases by 6.5 times. Next to education it is the income of the respondents which is a significant factor with Exp beta value 5.304, implying that when an respondents shift from a lower income group to a higher income group his willingness to adapt digitalization increase by 5.30 times. The mode of payment adopted by the respondents have a significant level of (.075) and the exp beta is 1.724, which reveals that as the respondents use more cashless 
methods of payment the adaptability for digitalization increases by 1.7 times. Occupation of the respondents have a significant value of .046 , and the exp beta value is .136 , which show that if the bamboo crafting is a secondary occupation then the adaptability for digitalized payment increases by 0.13 times then the one who take up bamboo crafting as a primary occupation. The other variables are found to be insignificant in influencing the willingness for adapting digitalized mode of payment.

\section{Conclusion}

When the government is emphasising the process of digitalization to make the economy more transparent there is a need to increase the level of adaptability of the people to the new system. The economic activities carried out by every section of the people need to be digitalized so that the economy becomes more transparent and there will be least possibilities of linkages. To make the system more adaptive in nature it is necessary to identify the factor that creates difficulties in adapting the system. This study has highlighted the small traders of Barpeta district of Assam. The majority of the traders are engaged in bamboo crafting business and most of them are of young age, having an enthusiasm to learn new things and adapt changes. This is a positive sign toward the digitalization process. The gap between the digitalized and non- digitalized section can be filled by boosting the awareness about the digitalized system by providing proper training facilities regarding the use of various electronic mode of financial transaction for the small and medium size enterprises. This study tries to bring into light the socio- economic factors that need to be focused in making the digitalization more adaptive in nature, it have been found that the education level is one of the prime socio-economic factor that need to be focus which will prove helpful in improving the financial literacy of the people. As a large number of economics activities are being executed in rural and semi urban areas of the country which need to be brought under the preview of digitalization progress. Otherwise a huge amount of transaction activities will not be reported in a transparent screen.

The study has some limitations in generalizing the result of the study, as there are many other factors that may affect the adaptability capacity of the people to the new system of digitalization. Importantly this study has at least considered few of them. Other factors affecting adaptation towards digital payment can be added to future research models. Another limitation of the study is that the selected sample cannot possibly represent the entire population completely. Hence generalization of the result will not be feasible.

Some policy implications can be derived from this work, Namely the importance of adaptability of digitalized mode of payment by the local people makes it clear to the government that it needs to take some policy measures to make the digitalized system more users friendly and trustworthy. The government of India have taken some measures to attract the people towards the digital mode of payment by introducing certain schemes such as Lucky Grahak Yojana and Digi-Dhan Vyapar Yojana. They have offered some amount of cash benefit to the users of digitalized mode of payment. In this context it can be stated that policymakers should adopt measures to promote more digital mode of payment among the small traders by investing more training and awareness programme. This policy derivation is important for the remote areas of the country as investment in digitalizing the locals' people of the remote areas can help to reduce the regional inequalities in term of growth.

\section{REFERENCES}

[1] Aggarwal, D \& Gupta, D. (2014). "Awareness of Financial Literacy Among College Students". Journal of Management Sciences and Technology. 2 (1), $1-13$.

[2] Arif, K. (2015). "Financial Literacy and Other Factors Influencing Individuals' Investment Decision: Evidence from A Developing Economy". Journal of Poverty, Investment and Development. 12(2), 74-84.

[3] Assam chief minister's Jeevanjyoti Swaniyojan Yojana, Assam April $26 \quad 2014$, https://www.assams.info/assam/chief-ministers-jeevan-jyoti-swaniyojan-yojana.

[4] Anderson, R.P.,.Jin,R. and Grunkemeie, R.(2003). "Understanding Logistic Regression Analysis in Clinical Report". The statistician's Page, vol 75,no 3,pp 753 -757. 
[5] Alzen. J.L., Langdon. L.S. and Otero.V.K (2018). "A logistic regression investigation of the relationship between the learning assistant model and failure rates in Introductory STEM courses". International Journal of STEM Education, Vol 5, no 1.

[6] Boamah, J.A. (2015). "Predicting Social Trust with Binary Logistic Regression". Research in Higher Education Journal. Vol 27, No-1.

[7] Bora,M.(2017). "Digital India: Concept and Implication". International Journal of Creative Research Thoughts. Vol 5. No 4. Pp 922-927.

[8] Caruana, J. (2016). Financial inclusion and the Fintech Revolution: Implications for Supervision and Oversight. Paper presented in Third GPFI-FSI Conference on Standard-Setting Bodies and Innovative Financial Inclusion, 26 October, Basel.

[9] Finau, G., Rika, N., Samuwai, J., \& Mcgoon, J. (2016). Perceptions of Digital Financial Services in Rural Fiji. Information Technologies \& International Development. 12(4), 11 -21.

[10] Ghaffar, S., and Sharif, S. (2016). The Level of Financial Literacy in Pakistan. Social Science Research Network. available at http://ssrn.com/Abstract=2724533,1-29. Accessed on 12/5/18.

[11] Hans, V.B. (2018). Digital Empowerment and Inclusive Growth. National Conference on "Digital Empowerment for Inclusive Growth and Sustainable Development. https://www.researchgate.net/publication/323691812_digital_empowerment_and_inclusive_growth. Accessed on 16/6/18.

[12] Hariss, C., Straker, L, and Pollock, C. (2017). A socioeconomic related 'digital divide' exists in how, not if, young people use computers. PLos One. 12(3).

[13] Hosmer, D. W., Lemeshow, S. A., and Sturdivant, R. X, (2013). Applied Logistic Regression, Wiley Publication.

[14] Huang,Y.(2017). Is inclusive growth in a digitalized world achievable? https://asiatimes.com/2017/07/inclusive-growth-digitalized-world-achievable/ Accessed on 24/5/18.

[15] Jain.C.(2018). Digital Payment and Demonetisation. International Journal of Research and Analytical Reviews. 5(1), 118-121.

[16] Joshi. M.C and Desai J.N.(2017). Digital Payment System: Before, During and After Demonetization. https:www.reasearchgate.net/publication/331001070. Accessed on 22/3/19.

[17] Jung,J. (2015). Digital Inclusion and Economic Development: A Regional Analysisfrom Brazil. The Global Information Technology Report 2015. https://www.weforum.org/reports/global-information-technologyreport-2015. Accessed on 12/6/19.

[18] Kuek, A., and Barwon, S.H. "Healthcare staff digital literacy levels and their attitudes towards information systems".Health Informatics Journal 1-21. DOI: 10.1177/1460458219839613.

[19] Malady, L. (2016). "Consumer Protection Issues for Digital Financial Services in Emerging Markets". Banking \& Finance Law Review. 31(2), 389-401.

[20] Malhotra, N K. (1984). "The Use of Linear Logit Models in Marketing Research", Journal of Marketing Research ,Vol. 21, No. 1 pp. 20-31.

[21] Maddala, G. S. (1919). "A Perspective on the Use of Limited-Dependent and Qualitative Variables Models in Accounting Research". The Accounting Review. Vol. 66, No. 4 pp. 788-807.

[22] Maji, P. (2017), Demonetisation keeps digital Payments up: Cashless Transaction Grows, Business Today, November 7th, 2017, New Delhi.

[23] Natasa Urbancikova, N. Manakova, N \& Bielcheva, G. (2017). "Socio-Economic and Regional Factors of Digital Literacy Related to Prosperity". QualityInnovation Prosperity. 21(2):124-141.

[24] NITI Aayog announces launch of the schemes - Lucky Grahak Yojana and Digi-Dhan Vyapar Yojana - for incentivising digital payment, Press Information Bureau Government of India NITI Aayog 15-December2016. Accessed on 25/6/18. https://pib.gov.in/newsite/PrintRelease.aspx?relid $=155418$.

[25] Panigrahi, M. (2019). Strategizing for Transformation. http://humancapitalonline.com/coverstories/details/541/-digital-fusion-strategizing-for-transformation. Accessed on 2/5/2020.

[26] Peng, C.J., Harry, T.S., Stage, F.K. and John, E.P. (2002). "The Use and Interpretation of Logistic Regression in Higher Education Journals, Research in High Education". Vol 43 No 1, pp 259-293.

[27] Prasad, H. and Meghwal, D. (2017). Digital Financial Literacy: A Study of Households of Udaipur. Global Journal of Advance Research, 4(5), 201-209.

[28] Punwatkar, S. and Verghese,M. (2018). Adaptation of e-Wallet Payment: An Empirical Study on Consumers Adoption Behavior in Central India, International Journal of Advanced in Management, Technology and Engineering Science, 8(3).

[29] Ramosacaj, M., Hasani, V., and Dumi,A. (2015). "Application of Logistic Regression in the Study of Students' Performance Level: Case Study of Vlora University". Journal of Educational and Social Research, Vol 5, No 3.

[30] Razdan.D. (2016). Digital and Cashless Economy : A New Way of Life after demonetization. Press Information Bureau Government of India Special Service and Features http://pib.nic.in/newsite/printrelease.aspx?relid=155605. Accessed on 23/6/18. 
[31] Sperandei,S. (2014). "Understanding logistic Regression Analysis". Biochemia Medica. Vol 24. No 1. pp $12-18$.

[32] Wyman, O. (2017). Accelerating Financial Inclusion in South East Asia wth Digital Finance. Adb.org/publication/financial-inclusion-south-east-asia-digital-finance. Accessed on 16/5/20.

\section{Appendix}

\begin{tabular}{|l|l|}
\hline Figure number & Captions of the figure \\
\hline Figure 1 & $\begin{array}{l}\text { Distribution of respondent according to their } \\
\text { age }\end{array}$ \\
\hline Figure 2 & $\begin{array}{l}\text { Distribution of respondent according to their } \\
\text { monthly income }\end{array}$ \\
\hline Figure 3 & $\begin{array}{l}\text { Distribution of respondents according to their } \\
\text { education qualification }\end{array}$ \\
\hline Figure 4 & $\begin{array}{l}\text { Distribution of the respondents according to } \\
\text { their mode of financial transactions }\end{array}$ \\
\hline Figure 5 & $\begin{array}{l}\text { Distribution of respondents according to their } \\
\text { confident level in using the ATM }\end{array}$ \\
\hline Figure 6 & $\begin{array}{l}\text { Distribution of respondents according to their } \\
\text { willingness to use Electronic Data Capturing } \\
\text { Machine }\end{array}$ \\
\hline Table number & \multicolumn{2}{|c|}{ Captions of tables } \\
\hline Table I & Hodel Summary \\
\hline Table II & Variables in the Equation (Result of the logit model) \\
\hline Table III
\end{tabular}

